\title{
BMJ Open Prevalence of undiagnosed diabetes mellitus and associated factors among adult residents of Bahir Dar city, northwest Ethiopia: a community-based cross-sectional study
}

\author{
Getasew Mulat Bantie, ${ }^{1}$ Achenef Almaw Wondaye, ${ }^{1}$ Efrem Beru Arike, ${ }^{1}$ \\ Mesfin Tenagne Melaku, ${ }^{1}$ Simegnew Tilaneh Ejigu, ${ }^{1}$ Abel Lule, ${ }^{1}$ \\ Wondemagegn Mulu Lingerew, ${ }^{2}$ Koku Sisay Tamirat (D) ${ }^{3}$
}

To cite: Bantie GM, Wondaye AA, Arike EB, et al. Prevalence of undiagnosed diabetes mellitus and associated factors among adult residents of Bahir Dar city, northwest Ethiopia: a community-based cross-sectional study. BMJ Open 2019;9:e030158. doi:10.1136/ bmjopen-2019-030158

- Prepublication history for this paper is available online. To view these files, please visit the journal online (http://dx.doi. org/10.1136/bmjopen-2019030158).

Received 09 March 2019 Revised 26 August 2019 Accepted 30 September 2019

Check for updates

(C) Author(s) (or their employer(s)) 2019. Re-use permitted under CC BY-NC. No commercial re-use. See rights and permissions. Published by BMJ.

${ }^{1}$ Public Health, GAMBY College of Medical Sciences, Bahir Dar, Ethiopia

${ }^{2}$ Microbiology and Immunology, College of Medicine and Health Science,Bahir Dar University, Bahir Dar, Ethiopia

${ }^{3}$ Epidemiology and Biostatistics, Institute of Public Health,

College of Medicine and Health Science, University of Gondar, Gondar, Ethiopia

Correspondence to Mr Koku Sisay Tamirat; kokusisay23@gmail.com

\section{ABSTRACT}

Objective To assess the prevalence of undiagnosed diabetes mellitus (DM) and associated factors among adult inhabitants of Bahir Dar city, northwest Ethiopia.

Design A community-based cross-sectional study was conducted on adults $(n=607)$ of Bahir Dar city from 10 March to 20 May 2018.

Measurements Data were collected using structured interviewer-administered questionnaire, and anthropometric measurements were taken from each participant. Fasting blood sugar (FBS) level was determined by samples taken early in the morning and readings of $F B S \geq 126 \mathrm{mg} / \mathrm{dL}$ were classified as diabetes. The multivariate logistic regression model was fitted to identify the predictors of undiagnosed DM; adjusted OR (AOR) with a $95 \% \mathrm{Cl}$ was computed to assess the strength of associations.

Result The study revealed that the prevalence of undiagnosed DM was $10.2 \%$ with $95 \% \mathrm{Cl} 7.9$ to 12.9 . Ever checked blood glucose level $(\mathrm{AOR}=1.91,95 \% \mathrm{Cl} 1.03$ to $3.51)$, don't know the symptoms of diabetes ( $\mathrm{AOR}=2.06$, $95 \% \mathrm{Cl} 1.08$ to 3.89 ), family history of DM (AOR=2.5, $95 \% \mathrm{Cl} 1.21$ to 5.18 ) and body mass index (BMI) $\geq 25 \mathrm{~kg} /$ $\mathrm{m}^{2}$ (AOR=1.98, 95\% $\mathrm{Cl} 1.09$ to 3.60) were factors associated with undiagnosed DM.

Conclusion The magnitude of undiagnosed diabetes was high. Family history of DM, ever checked blood glucose level, don't know about the symptoms of diabetes and overweight BMI were predictors of undiagnosed DM. Hence, screening and treatment are mandatory for high-risk groups. In addition, this study suggests frequent screening for those with family history and awareness creating about the disease for early detection and treatment.

\section{INTRODUCTION}

Diabetes mellitus (DM) is a metabolic disorder of multiple aetiologies characterised by chronic hyperglycaemia induced from defects of insulin secretion and action or both. ${ }^{1}$ Over 425 million people are currently living with diabetes, and the burden is projected to be

\section{Strengths and limitations of this study}

- As this is a community-based work with an adequate sample its finding is highly generalisable for the city and the study might be used as an entry into the screening programme of diabetes among highrisk groups.

- Participants diagnosed with diabetes during the community screening were linked to nearby health facilities for further follow-ups and treatment.

- The study did not show the overall magnitude since it excluded known patients with diabetes.

- Some risk factors with known association with diabetes mellitus, for example, cholesterol level was not assessed and a single fasting blood glucose measurement was used without $\mathrm{HbA} 1 \mathrm{c}$, might have resulted in a misclassification, owing to conditional blood glucose variation.

- In this community-based study conducted through house-to-house visits, women had more chances of being selected than men who usually worked outdoors. Thus, under-reporting of sensitive issues such as smoking and khat chewing (which men are often more likely to indulge in) might have introduced information bias.

529 million by $2030 .^{2}{ }^{3}$ Globally, 1.6 million deaths were attributed to diabetes in $2015 .^{2}$ Type 2 diabetes, which is largely preventable through regular physical activity, healthy balanced diet and improved living environments, is the most common. ${ }^{1}$ The magnitude and incidence of diabetes has risen rapidly, especially in low and middle-income countries such as sub-Saharan Africa. ${ }^{45}$ In recent years, non-communicable diseases are becoming the problem in low and middle-income countries due to increased urbanisation and epidemiological transitions. ${ }^{24}$ Besides, DM has been the leading cause of morbidity and mortality in 
association with numerous complications, like blindness, kidney failure, heart attacks, stroke and lower limb amputation. ${ }^{6-8}$ Sometimes, diabetes is associated with complications such as foot ulcer, retinopathy and heart attack which are means of the identification of undiagnosed DM. ${ }^{69}$

Early diagnosis and treatment are the key interventions to prevent the complications and deaths from diabetes as well as for better treatment outcomes. However, globally one in two peoples living with diabetes remain undiagnosed. ${ }^{1}$ Late diagnosis and treatment of DM is associated with the increased occurrence of acute and chronic complications. ${ }^{10}$ Complications from undiagnosed diabetes lead to a substantial decrease in patients' quality of life which are usually preventable through early identification of risk factors. ${ }^{2}$ According to the 2014 report, about 179.2 million people lived with undiagnosed DM worldwide. The African region has the highest percentage of undiagnosed people compared with other regions. About $62.3 \%$ of the people with the diseases do not know their being affected, and about 13.4 million had undiagnosed DM. ${ }^{411}$ In Ethiopia, the magnitude of diabetes is increasing; according to the WHO report, the number of cases was 800000 in 2000, and is rising to an estimated 1.8 million by $2030 .{ }^{12-14}$ Evidence from studies conducted in Gondar, northwest Ethiopia, showed that 2.3\% of the individuals lived with undiagnosed DM. ${ }^{15}$ Factors such as educational level, body mass index (BMI), family history and the presence of other chronic illnesses have been associated with undiagnosed DM..$^{10-20}$ In addition, low health-seeking behaviour, like lack of regular health check-ups, also contributed to undiagnosed diabetes. Though a number of studies were conducted in different parts of the country, nothing has been done in the setting we have chosen.

Therefore, this study aimed to determine the prevalence of undiagnosed DM and associated factors among Bahir Dar city residents to try to help policymakers carry out evidence-based interventions and institute communitybased screening programmes.

\section{METHODS}

\section{Design, setting and period}

A community-based cross-sectional study was conducted in Bahir Dar city from 10 March to 20 May 2018. The city is located $565 \mathrm{~km}$ from Addis Ababa, the capital of Ethiopia. According to the population and household survey, it had 249851 inhabitants served by two (one public and one private) hospitals, eight health centres and six private clinics.

\section{Population, sample and sampling method}

Adults aged 18 years and above living in the city and its selected subcities were the source and study populations, respectively. Individuals with previous diagnosis of diabetes and follow-ups were excluded. The sample size for this study was determined by using the single population proportion with the assumptions of $50 \%$ proportion of undiagnosed DM for lack of previous works in the study setting, 5\% margin of error and 1.5 design effect which yielded 607 . The multistage sampling technique was employed, and three subcities (Shimbet, Shumabo and Hidar 11) were randomly selected out of the nine in the study area. Samples were proportionally assigned to each of the selected subcities based on the number of households. Thus, 171, 202 and 234 participants were selected from Shimbet, Shumabo and Hidar 11, respectively, using the systematic random sampling technique. In households which had more than one eligible individual the lottery method was used to select one study.

\section{Data collection procedures and measurement of variables}

The data collection tool was initially prepared in English and translated to the local language Amharic. Nine laboratory professionals (six data collectors and three supervisors) were recruited and trained by the principal investigator on the objective of the study on how to collect blood samples. The questionnaire contained sociodemographic, behavioural and clinical characteristics developed after a review of literature. Data were collected using a pretested structured interviewer-administered method, and anthropometric measurements such as weight and height were taken from each participant. After data collection participants were instructed to be on overnight fasting (10-16hours). In the early morning of the next day, data collectors drew 3-5 mL of blood from each participant, and fasting blood glucose level was measured using the glucose oxidase-6 phosphate dehydrogenase method.

Participants who had fasting glucose levels of $126 \mathrm{mg} /$ $\mathrm{dL}$ or above were classified as diabetic, while those who had between 100 and $125 \mathrm{mg} / \mathrm{dL}$ taken were considered as 'impaired fasting glucose' (IFG) cases.

\section{Data processing and analysis}

Data were cleaned, coded and entered using EpiData V.3.1 and exported to SPSS V.20 for further management and analysis. Descriptive statistics, such as means, medians and percentages, presented in tables and texts were used to summarise the characteristics of participants. Bivariate and multivariable logistic regression analyses were employed to identify factors associated with undiagnosed diabetes, which was the response variable, whereas sociodemographic characteristics (age, educational level, religion, ethnicity, marital status and monthly income), behavioural characteristics (smoking status, khat chewing habit, alcohol intake) and clinical characteristics (BMI, history of hypertension, family history of DM) were the independent variables. The bivariable regression model was initially fitted to compute the crude OR, and variables with $p$ values less than 0.2 were entered into multivariable logistic regression model to control potential confounding effects in the model. The strength of associations between independent and outcome variables was assessed using the adjusted OR (AOR) with a 95\% CI. Variables with $\mathrm{p}$ values less than 0.05 in the multivariable analysis were considered as statistically significant predictors of undiagnosed DM. 
Patient and public involvement

Patients were not involved in the study.

\section{RESULT}

Sociodemographic and behavioural characteristics

A total of 607 participants furnished data for the final analysis with a response rate of $100 \%$. The mean age of the participants was $35.2( \pm 13.8)$ years; about $13.5 \%$ of participants had no formal education; the majority (96.7\%) were Orthodox Christians, and most (98.2\%) were from Amhara. More than half $(61 \%)$ of the participants were married, and $42.3 \%$ had a monthly income of above 2400 Ethiopian birr; $50.2 \%$ had history of moderate alcohol intake, $2.7 \%$ chewed khat and $1.5 \%$ smoked cigarette, the most common self-reported substance use. One hundred and seventy-eight (29.3\%) of the participants performed physical exercises, of whom $66.3 \%$ performed physical exercises three to six times per week (table 1).

Table 1 Sociodemographic and behavioural characteristics of study participants in Bahir Dar city, northwest Ethiopia ( $\mathrm{n}=607)$

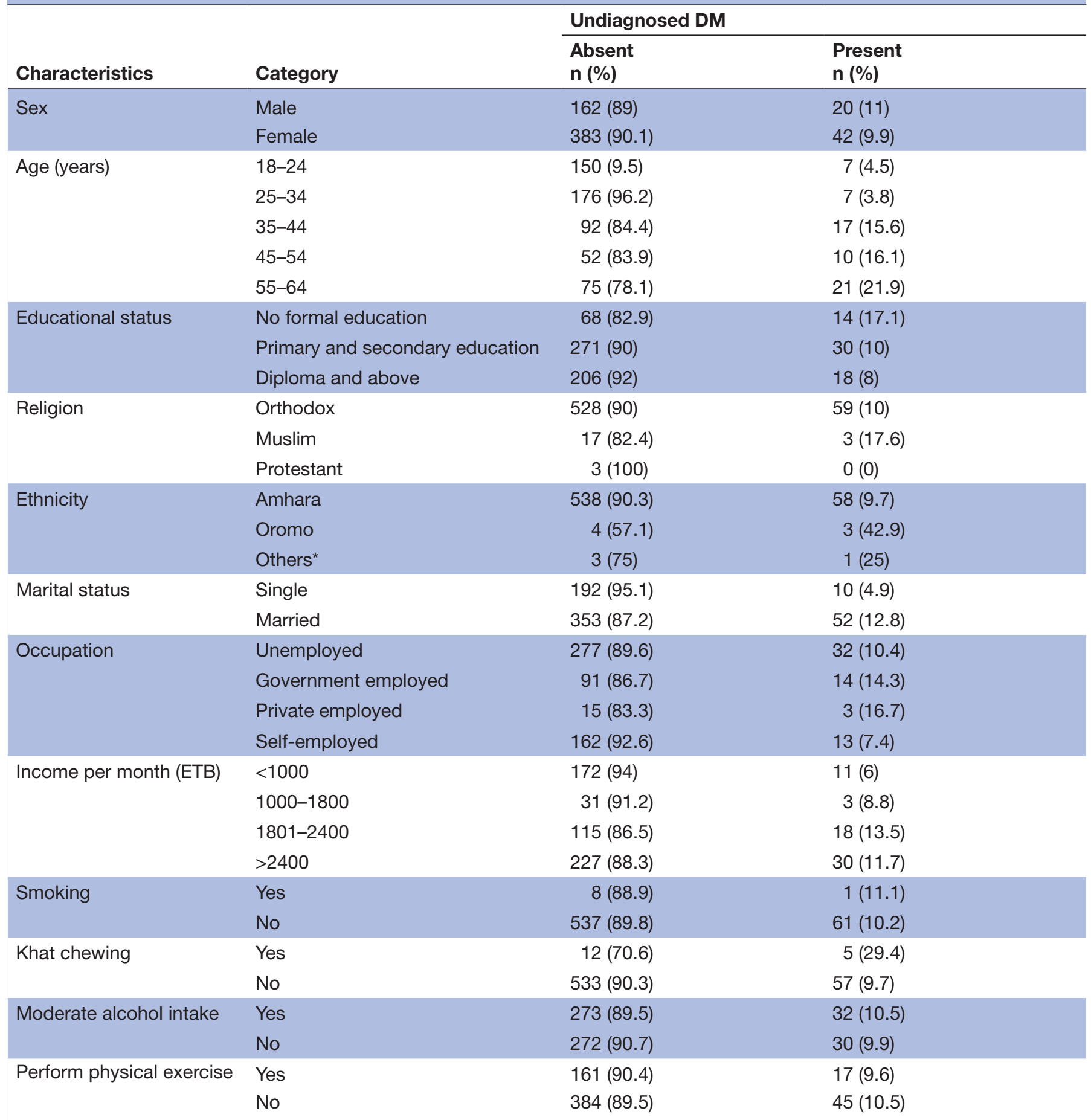

*Tigray and Agew.

DM, diabetes mellitus; ETB, Ethiopian birr. 
Table 2 Clinical characteristics and laboratory measurements of study participants in Bahir Dar city, northwest Ethiopia $(n=607)$

\begin{tabular}{|c|c|c|c|}
\hline \multirow[b]{2}{*}{ Characteristics } & \multicolumn{2}{|c|}{ Undiagnosed DM } & \multirow[b]{2}{*}{$\begin{array}{l}\text { Overall } \\
\text { percentage }\end{array}$} \\
\hline & $\begin{array}{l}\text { Absent } \\
\text { n (\%) }\end{array}$ & $\begin{array}{l}\text { Present } \\
\text { n (\%) }\end{array}$ & \\
\hline \multicolumn{4}{|c|}{ Ever checked your blood sugar level } \\
\hline Yes & $170(82.5)$ & $36(17.5)$ & 33.9 \\
\hline No & $375(93.5)$ & $26(6.5)$ & 66.1 \\
\hline \multicolumn{4}{|c|}{ The checked blood sugar level in the last month } \\
\hline Yes & $16(72.7)$ & $6(27.3)$ & 3.6 \\
\hline No & $529(90.4)$ & $56(9.6)$ & 96.4 \\
\hline \multicolumn{4}{|c|}{ Family history of DM } \\
\hline Yes & $63(80.8)$ & $15(19.2)$ & 12.9 \\
\hline No & $482(91.1)$ & $47(8.9)$ & 87.1 \\
\hline \multicolumn{4}{|l|}{$\begin{array}{l}\text { Diagnosis of } \\
\text { hypertension }\end{array}$} \\
\hline Yes & $30(68.2)$ & $14(31.8)$ & 8.2 \\
\hline No & $515(91.5)$ & $48(8.5)$ & 92.8 \\
\hline \multicolumn{4}{|l|}{$\begin{array}{l}\text { Know symptoms } \\
\text { of DM }\end{array}$} \\
\hline Yes & $224(92.2)$ & $19(7.8)$ & 40 \\
\hline No & 321 (88.2) & 43 (11.8) & 60 \\
\hline \multicolumn{4}{|c|}{ Body mass index (BMI), kg/m² } \\
\hline$\leq 24.9$ & 376 (93.3) & 27 (6.7) & 64.5 \\
\hline$\geq 25$ & 169 (82.8) & 35 (17.2) & 34.5 \\
\hline
\end{tabular}

DM, diabetes mellitus.

\section{Clinical characteristics and undiagnosed DM}

More than one-third (35.4\%) of the participants had BMI of $25 \mathrm{~kg} / \mathrm{m}^{2}$ and above; $12.9 \%$ had a family history of DM, and $8.2 \%$ had previous diagnosis of hypertension. About $33.9 \%$ of the participants had checked their blood glucose level previously; $3.6 \%$ checked last month. Two hundred and forty-three $(40 \%)$ of the participants knew the symptoms of diabetes, of which polyuria, polydipsia, polyphagia and fatigue formed $19.8 \%, 29.6 \%, 35.6 \%$ and $16 \%$ of the most commonly mentioned symptoms.

The prevalence of undiagnosed DM was found to be $10.2 \%$ with $95 \%$ CI 7.9 to 12.9 , with a fasting blood glucose level $\geq 126 \mathrm{mg} / \mathrm{dL}$. In addition, the magnitude of IFG was $12.8 \%$ with $95 \%$ CI 10.3 to 15.7 , with a fasting blood glucose level between 100 and $125 \mathrm{mg} / \mathrm{dL}$ (table 2).

\section{Factors associated with undiagnosed diabetes}

In the univariate logistic regression analysis, age, marital status, level of education, ever checked blood glucose level, family history of DM, had hypertension, BMI $\geq 25 \mathrm{~kg} /$ $\mathrm{m}^{2}$ and those who don't know about the symptoms of DM were factors associated with undiagnosed diabetes at $20 \%$ of level of significance. In the multivariable logistic regression analysis, only family history of DM, ever checked blood glucose level, know about symptoms of
$\mathrm{DM}$ and $\mathrm{BMI} \geq 25 \mathrm{~kg} / \mathrm{m}^{2}$ were predictors of undiagnosed $\mathrm{DM}$ at $\mathrm{p}=0.05$.

Accordingly, for those participants who do not know the symptoms of DM, the odds of undiagnosed diabetes were 2.06 (AOR=2.06, 95\% CI 1.08 to 3.89) times higher compared with those who know. Similarly, those participants who had family history of DM had 2.5 (AOR=2.5, 95\% CI 1.21 to 5.18) times higher odds of undiagnosed diabetes compared with those who had no such history. For the participants who had ever checked their blood glucose level previously, the odds of undiagnosed DM were 1.91 (AOR=1.91, 95\% CI 1.03 to 3.51) times higher compared with those who had not checked their blood glucose level. Moreover, participants who had BMI $\geq 25 \mathrm{~kg} /$ $\mathrm{m}^{2}$ and above were 1.89 (AOR=1.89, 95\% CI 1.04 to 3.43 ) times more likely to have undiagnosed DM compared with those who had BMI below $24.9 \mathrm{~kg} / \mathrm{m}^{2}$ (table 3 ).

\section{DISCUSSION}

This study revealed that the magnitude of undiagnosed diabetes was $10.2 \%$. Family history of DM, ever checked blood glucose level, 'don't know about symptoms of diabetes' and overweight BMI were the predictors of undiagnosed DM. The magnitude noted was consistent with those of studies conducted in East Gojjam zone, northwest Ethiopia (11.5\%), ${ }^{19}$ Germany $(8.2 \%),{ }^{21}$ Malaysia $(8.9 \%),{ }^{10}$ USA $(11.5 \%),{ }^{7}$ Quebec, Canada $(5.6 \%),{ }^{22}$ Italia $(10 \%)^{8}$ and from the subgroup analysis of African urban population $(8.68 \%){ }^{23}$

However, our finding was higher than that of a study at Koladiba (2.3\%),15 Bishoftu town $(5 \%)^{17}$ and Addis Ababa of Ethiopia (6.6\%), ${ }^{13}$ pooled estimate of African population $(5.37 \%)$, Teheran, Iran $(5 \%)^{24}$ and Qatar $(5.9 \%) .{ }^{25}$ However, our result was lower than those of patients with undiagnosed DM and hypertension in Kenya $(14 \%)$ and India $(15 \%) .{ }^{26}$ The possible explanation for these differences in sociodemographic characteristics might be study settings, lifestyles, health-seeking behaviour and practice in relation to routine screening of diabetes and other health problems. Particularly, our finding was markedly higher than that of the previous study in Koladiba, a rural district in northwest Ethiopia. ${ }^{15}$ The possible explanation for this difference might be variations in study populations, that, is the other studies included rural residents whose magnitude of DM was lower. Our study was conducted entirely among urban residents whose magnitude of DM was relatively higher and exposed to numerous risk factors. In addition, the measurement tool used to determine fasting blood glucose level by the other studies was HbAlc, which was more reliable, whereas our study was based on a single measurement which might fluctuate due to different factors.

This study also found that the magnitude of IFG was $12.85 \%$, showing that unless appropriate interventions were made, the individuals might develop diabetes. The finding was consistent with population based study in 
Table 3 Univariate and multivariable logistic regression analysis to identify factors associated with undiagnosed diabetes among residents of Bahir Dar city, Ethiopia, 2018 ( $n=607)$

\begin{tabular}{|c|c|c|c|c|c|}
\hline \multirow[b]{2}{*}{ Variables } & \multicolumn{2}{|c|}{ Undiagnosed DM } & \multirow[b]{2}{*}{ COR $(95 \% \mathrm{Cl})$} & \multirow[b]{2}{*}{ AOR $(95 \% \mathrm{Cl})$} & \multirow[b]{2}{*}{$P$ value } \\
\hline & Yes & No & & & \\
\hline \multicolumn{6}{|l|}{ Marital status } \\
\hline Single & 10 & 192 & 0.35 (0.17 to 0.71$)$ & 0.69 (0.27 to 1.76$)$ & 0.44 \\
\hline Ever married & 52 & 353 & 1 & 1 & \\
\hline \multicolumn{6}{|l|}{ Age (years) } \\
\hline $18-24$ & 7 & 150 & 1 & 1 & \\
\hline $25-34$ & 7 & 176 & 0.85 (0.29 to 2.48 ) & 0.53 (0.16 to 1.76$)$ & 0.30 \\
\hline $35-44$ & 17 & 92 & 3.96 (1.58 to 9.91$)$ & 1.93 (0.62 to 6.0$)$ & 0.25 \\
\hline $45-54$ & 10 & 52 & 4.12 (1.49 to 11.38$)$ & 1.79 (0.51 to 6.30$)$ & 0.36 \\
\hline $55-64$ & 21 & 75 & $6.0(2.44$ to 14.74$)$ & 2.08 (0.63 to 6.90$)$ & 0.22 \\
\hline \multicolumn{6}{|l|}{ Level of education } \\
\hline No formal education & 14 & 68 & 1 & 1 & \\
\hline Primary and secondary & 30 & 271 & $0.53(0.27$ to 1.06$)$ & 0.84 (0.38 to 1.83 ) & 0.66 \\
\hline Diploma and above & 18 & 206 & 0.42 (0.20 to 0.89$)$ & 0.81 (0.33 to 1.97$)$ & 0.64 \\
\hline \multicolumn{6}{|l|}{ Ever checked blood glucose* } \\
\hline Yes & 36 & 170 & 3.05 (1.78 to 5.22$)$ & 1.91 (1.03 to 3.51 ) & 0.037 \\
\hline No & 26 & 375 & 1 & 1 & \\
\hline \multicolumn{6}{|l|}{ Family history of $\mathrm{DM}^{*}$} \\
\hline Yes & 15 & 63 & 2.44 (1.29 to 4.62$)$ & 2.50 (1.21 to 5.18$)$ & 0.013 \\
\hline No & 47 & 482 & 1 & 1 & \\
\hline \multicolumn{6}{|l|}{ History of hypertension } \\
\hline Yes & 14 & 30 & 5.0 (2.48 to 10.08$)$ & 2.02 (0.91 to 4.53 ) & 0.085 \\
\hline No & 48 & 515 & 1 & 1 & \\
\hline \multicolumn{6}{|l|}{ BMI $\left(\mathrm{kg} / \mathrm{m}^{2}\right)^{*}$} \\
\hline$\leq 24.9$ & 27 & 376 & 1 & 1 & \\
\hline$\geq 25$ & 35 & 169 & 2.88 (1.69 to 4.91$)$ & 1.89 (1.04 to 3.43 ) & 0.035 \\
\hline \multicolumn{6}{|l|}{ Know symptoms of $\mathrm{DM}^{\star}$} \\
\hline Yes & 19 & 224 & 1 & 1 & \\
\hline No & 43 & 321 & 1.57 (0.89 to 2.78$)$ & 2.06 (1.08 to 3.89 ) & 0.026 \\
\hline
\end{tabular}

*Shows a pvalue less than 0.05 .

AOR, adjusted OR; BMI, body mass index; COR, crude OR; DM, diabetes mellitus.

Qatar (12.5\%). ${ }^{25}$ However, this finding was lower than that of a study conducted in Denmark $(27.1 \%)^{27}$ and Bukittinggi, Indonesia (32\%). ${ }^{28}$ The possible explanations might be sociodemographic of living habit variations. The study was conducted among dental patients in Denmark whose diabetes was often associated with complications, like periodontitis and gingival ulcer.

Although the causes of diabetes are not fully understood but it has a strong link with overweight, obesity, increasing age as well as family history. ${ }^{12}$ This statement is supported by different studies, including the present one. Our study revealed that family history of DM was associated with three times increased odds of getting undiagnosed diabetes compared with participants with no such history. This finding was consistent with those of studies conducted in East Gojjam, Ethiopia and India. ${ }^{12} 1926$ This could be generally attributed to the linkage of diabetes with genetics. Nevertheless, other types of DM may also be associated with family history in relation to behaviour such as living habit and physical inactivity which may predispose to diabetes. Similarly, among those who did not check their blood glucose level, the odds of getting undiagnosed diabetes were two times higher compared with those who checked their blood glucose level. This could be due to the fact that those who practised routine screening for DM might have had greater risk factors for the disease.

Moreover, those who did not know about the symptoms of diabetes were associated with increased occurrence of undiagnosed DM compared with those who knew about 
the symptoms. This finding was consistent with those of other studies in Ethiopia. ${ }^{29}$ This could be explained by the fact that low knowledge symptoms might affect health-seeking behaviour and regular screening practice might be associated with high rates of hidden/undiagnosed diabetes.

For participants with BMI $\geq 25 \mathrm{~kg} / \mathrm{m}^{2}$, undiagnosed DM was twice higher than those whose BMI was less than $\geq 25 \mathrm{~kg} / \mathrm{m}^{2}$. This finding was consistent with those of other studies. ${ }^{4124}$ Overweight and obesity which ultimately lead to diabetes were associated with insulin resistance.

\section{Strengths and limitations of the study}

The strengths of this study were its being community based and involving an adequate sample. The finding might help as an entry into community screening programmes among high-risk groups. However, the study has limitations in that it did not show the actual overall magnitude of diabetes, as known patients with DM were excluded. This study was conducted on adults/a working age group in the city, and the range was 18-64 years which might have introduced selection bias. In addition, this study also has limitations in terms of sex disproportion which was due to the fact that the house-to-house visits involved more females than males who worked outdoors. Some risk factors which have significant associations with undiagnosed DM, like cholesterol level, were not included in this study. In addition, this study was based on a single fasting blood glucose measurement, and HbAlc was not used, perhaps introducing misclassification due to conditional blood glucose variations.

\section{CONCLUSION}

The magnitude of undiagnosed diabetes was high. Family history of DM, checking blood glucose level, not knowing about the symptoms of diabetes and overweight BMI were predictors of undiagnosed DM. Hence, screening and treatment are mandatory for high-risk groups. In addition, the study suggests frequent screening for those with family history and creating awareness about the disease for early detection and treatment.

Acknowledgements We thank our data collectors and the supervisor for their invaluable effort; without them, this study would not have been completed. Our deep gratitude also goes to our study participants who volunteered and took their time to give us all the relevant information for the study. Last but not least, we thank the Bahir Dar City Administrative Office for their cooperation and help during the data collection.

Contributors GMB, AAW, EBA, MTM, STE, AL, WML and KST conceived the study, approved the proposal with extensive revisions, participated in data analysis and had written the manuscript. The authors read and approved the final manuscript.

Funding The authors have not declared a specific grant for this research from any funding agency in the public, commercial or not-for-profit sectors.

Competing interests None declared.

Patient consent for publication Not required.

Ethics approval Ethical approval was obtained from GAMBY Medical and Business College, Research and Publication Office, with reference number GC-220/2010, and approval letter was obtained from Bahir Dar City Administrative Office. The purpose of the study was explained to the respondents and informed consent was obtained from them. Confidentiality of information was maintained by omitting any personal identifier from the questionnaires. The study participant information sheet was attached on the front page of the questionnaire and before the actual data collection process started, the participants were well informed and the data collection was on a voluntary basis. Those who screened to have DM during data collection were referred and linked to a nearby hospital.

Provenance and peer review Not commissioned; externally peer reviewed.

Data availability statement Data are available upon reasonable request.

Open access This is an open access article distributed in accordance with the Creative Commons Attribution Non Commercial (CC BY-NC 4.0) license, which permits others to distribute, remix, adapt, build upon this work non-commercially, and license their derivative works on different terms, provided the original work is properly cited, appropriate credit is given, any changes made indicated, and the use is non-commercial. See: http://creativecommons.org/licenses/by-nc/4.0/.

ORCID iD

Koku Sisay Tamirat http://orcid.org/0000-0001-6495-1882

\section{REFERENCES}

1 IDF. IDF diabetes atlas. International diabetes Federation; 2013.

2 Zhou B, Lu Y, Hajifathalian K, et al. Worldwide trends in diabetes since 1980: a pooled analysis of 751 population-based studies with 4.4 million participants. The Lancet 2016;387:1513-30.

3 Guariguata L, Whiting DR, Hambleton I, et al. Global estimates of diabetes prevalence for 2013 and projections for 2035. Diabetes Res Clin Pract 2014;103:137-49.

4 Hall V, Thomsen RW, Henriksen O, et al. Diabetes in sub Saharan Africa 1999-2011: epidemiology and public health implications. A systematic review. BMC Public Health 2011;11:564.

5 Motala A, Ramaiya K. Diabetes: the hidden pandemic and its impact on sub-Saharan Africa Diabetes leadership forum; 2010.

6 Cortez DNet al. Complications and the time of diagnosis of diabetes mellitus in primary care. Acta Paulista de Enfermagem 2015;28:250-5

7 Skeldon SC, Detsky AS, Goldenberg SL, et al. Erectile dysfunction and undiagnosed diabetes, hypertension, and hypercholesterolemia. Ann Fam Med 2015;13:331-5.

8 Ursini F, Russo E, D'Angelo S, et al. Prevalence of undiagnosed diabetes in rheumatoid arthritis: an OGTT study. Medicine 2016;95:e2552.

9 Koo BK, Lee C-H, Yang BR, et al. The incidence and prevalence of diabetes mellitus and related atherosclerotic complications in Korea: a national health insurance database study. PLoS One 2014;9:e110650.

10 Ismail Het al. Undiagnosed type 2 diabetes mellitus and its risk factors among Malaysians: National health and morbidity survey, 2011. International Journal of Public Health Research 2016;6:677-84.

11 Roglic G. Who global report on diabetes: a summary. Int J Noncommun Dis 2016;1.

12 Gebre MW. Diabetes mellitus and associated diseases from Ethiopian perspective: systematic review. Ethiopian Journal of Health Development 2013;27:249-53.

13 Tesfaye T, Shikur B, Shimels T, et al. Prevalence and factors associated with diabetes mellitus and impaired fasting glucose level among members of federal police Commission residing in Addis Ababa, Ethiopia. BMC Endocr Disord 2016;16:68.

14 Yemane Tet al. Type II diabetes mellitus in Jimma town, Southwest Ethiopia. Ethiopian Journal of Health Sciences 2007;17.

15 Worede A, Alemu S, Gelaw YA, et al. The prevalence of impaired fasting glucose and undiagnosed diabetes mellitus and associated risk factors among adults living in a rural Koladiba town, Northwest Ethiopia. BMC Res Notes 2017;10:251.

16 Aynalem SB, Zeleke AJ. Prevalence of diabetes mellitus and its risk factors among individuals aged 15 years and above in MizanAman town, Southwest Ethiopia, 2016: a cross sectional study. Int J Endocrinol 2018;2018:1-7.

17 Megerssa Yet al. Prevalence of undiagnosed diabetes mellitus and its risk factors in selected institutions at Bishoftu town, East Shoa, Ethiopia. J Diab Metab

18 Wakjira ZN, Beyene Berha A. Screening employees for undiagnosed type 2 diabetes mellitus and evaluation of risk scores in Tikur Anbessa specialized Hospital, Addis Ababa, Ethiopia. J Diabetes Metab 2017;08.

19 Wondemagegn AT, Bizuayehu HM, Abie DD, et al. Undiagnosed diabetes mellitus and related factors in East Gojjam (NW Ethiopia) in 2016: a community-based study. J Public Health Res 2017;6:834. 
20 Zenebe T, Merga H, Habte E. A community-based cross-sectional study of magnitude of dysglycemia and associated factors in Southwest Ethiopia. Int J Diabetes Dev Ctries 2019;387:1-7.

21 Rathmann W, Haastert B, Icks A, et al. High prevalence of undiagnosed diabetes mellitus in southern Germany: target populations for efficient screening. The KorA survey 2000. Diabetologia 2003;46:182-9.

22 Leong A, Dasgupta K, Chiasson J-L, et al. Estimating the population prevalence of diagnosed and undiagnosed diabetes. Diabetes Care 2013;36:3002-8.

23 Asmelash D, Asmelash Y. The burden of undiagnosed diabetes mellitus in adult African population: a systematic review and metaanalysis. J Diabetes Res 2019;2019:1-8.

24 Hadaegh F, Bozorgmanesh MR, Ghasemi A, et al. High prevalence of undiagnosed diabetes and abnormal glucose tolerance in the Iranian urban population: Tehran lipid and glucose study. BMC Public Health 2008;8:176.
25 Bener A, Zirie M, Janahi IM, et al. Prevalence of diagnosed and undiagnosed diabetes mellitus and its risk factors in a populationbased study of Qatar. Diabetes Res Clin Pract 2009;84:99-106.

26 Ramasamy J, Parthasarathy U. Prevalence of undiagnosed diabetes and prediabetes among voluntary blood donors in a tertiary health care setting. International Journal of Research in Medical Sciences 2016;4:2569-75.

27 Holm N-CR, Belstrøm D, Østergaard JA, et al. Identification of individuals with undiagnosed diabetes and pre-diabetes in a Danish cohort attending dental treatment. J Periodontol 2016;87:395-402.

28 Amelia D, Kurniawati D. Risk of type 2 diabetes mellitus among healthy individuals in tigo baleh and rasimah Ahmad area in Bukittinggi in 2017. Malaysian Journal of Medical Research 2018;2:42-6.

29 Kassahun CW, Mekonen AG. Knowledge, attitude, practices and their associated factors towards diabetes mellitus among non diabetes community members of bale zone administrative towns, South East Ethiopia. A cross-sectional study. PLoS One 2017;12:e0170040. 